\title{
Calcium and Sodium Transport and Vitamin D Metabolism in the Spontaneously Hypertensive Rat
}

Harold P. Schedl, Duane L. Miller, James M. Pape, Ronald L. Horst, and Helen D. Wilson

The Department of Medicine, Veterans Administration Medical Center, Iowa City, Iowa 52240, the National Animal Disease Laboratory, Ames, Iowa 50010, and the GastroenterologyHepatology Research Laboratories, University of Iowa, Iowa City, Iowa 52242

bstract. Serum ionized calcium levels are lower and immunoreactive parathyroid hormone levels are higher in the spontaneously hypertensive (SH) rat than in the normotensive Wistar-Kyoto (WKy) control. We postulated that there is either a defect in the regulation of vitamin $\mathrm{D}$ metabolism by parathyroid hormone or that the gut target organ for vitamin D in the SH rat is unresponsive. To test these hypotheses we measured serum concentrations of vitamin D metabolites and intestinal transport of calcium and sodium. Compared with that of WKy controls, in vitro calcium transport by duodenal sacs of the SH rat was decreased $(P<0.001)$ at $5 \mathrm{wk}$, before the development of hypertension, and at $12 \mathrm{wk}$, after hypertension was well established. When measured in vivo in the most proximal $20 \mathrm{~cm}$ of small intestine, maximum velocity $\left(V_{\max }\right)$ for calcium transport was decreased $(P<0.05)$ and net absorption of sodium and water was increased $(P<0.05)$ in SH rats as compared with WKy rats. $V_{\max }$ for calcium transport was also decreased $(P<0.05)$ in the most distal $20 \mathrm{~cm}$ of small intestine of $\mathrm{SH}$ rats, but net sodium and water transport were the same in SH and WKy rats. At 12 wk, serum concentration of 1,25-dihydroxycholecalciferol [1,25$(\mathrm{OH})_{2} \mathrm{D}_{3}$ ] was the same in both $\mathrm{SH}$ and WKy groups, but its precursor, 25-hydroxycholecalciferol, was increased $(P<0.05)$ in the SH rat. We conclude that in the SH rat: $(a)$ the concentration of $1,25-(\mathrm{OH})_{2} \mathrm{D}_{3}$ is inappro-

A preliminary report of this work was presented in part at the Annual Meeting of the American Society for Clinical Investigation, 2 May 1983, Washington, DC.

James Pape was a Medical Student Research Fellow.

Received for publication 12 August 1983 and in revised form 2 December 1983 .

The Journal of Clinical Investigation, Inc. Volume 73, April 1984, 980-986 priately low in relation to the elevated immunoreactive parathyroid hormone and the depressed calcium absorption, suggesting a defect in the regulation of vitamin D metabolism; and $(b)$ the depressed calcium absorption, in the setting of normal concentrations of $\left[1,25-(\mathrm{OH})_{2} \mathrm{D}_{3}\right]$, demonstrates unresponsiveness of the gut to vitamin $\mathrm{D}$ and may explain in part the low serum ionized calcium found in earlier studies. The presence of these abnormalities before we found a significant difference in blood pressure suggests that they may be causal, not secondary, to the hypertension.

\section{Introduction}

Evidence from many sources suggests that calcium has a role in hypertension. Dietary calcium intake is lower in patients with hypertension than in normotensive individuals $(1,2)$. In epidemiologic studies, low dietary calcium has been associated with hypertension $(3,4)$. Low calcium intake increases blood pressure in Wistar-Kyoto (WKy) ${ }^{1}$ rats (5), which are controls for the spontaneously hypertensive (SH) rats developed from this strain. High calcium intake lowers blood pressure in $\mathrm{SH}$ (6-8) and in WKy rats (6).

Total serum calcium is similar in patients with essential hypertension and normotensive controls, but serum ionized calcium is decreased in hypertensive patients (9). This is also true of SH rats as compared with WKy rats: under comparable feeding conditions, serum ionized calcium is lower in SH than in WKy rats $(7,10,11)$. Serum immunoreactive parathyroid hormone is elevated in patients with essential hypertension (12) and in SH rats (7). These findings suggest abnormalities in calcium homeostasis in hypertension; parathyroid hormone apparently increases appropriately in response to decreased ionized calcium

1. Abbreviations used in this paper: $1,25-(\mathrm{OH})_{2} \mathrm{D}_{3}, 1,25$-dihydroxycholecalciferol; 24,25- $(\mathrm{OH})_{2} \mathrm{D}_{3}, 24,25$-dihydroxycholecalciferol; 25-OH- $\mathrm{D}_{3}$, 25-hydroxycholecalciferol; S/M, serosal-to-mucosal; SH, spontaneously hypertensive; WKy, Wistar-Kyoto. 
in serum but fails to correct the decreased serum calcium concentration. Therefore, if the parathyroid response is adequate, either the regulation of formation of 1,25-dihydroxycholecalciferol $\left[1,25-(\mathrm{OH})_{2} \mathrm{D}_{3}\right]$ by parathyroid hormone is defective, or calcium absorption by the alimentary tract target organ is relatively unresponsive to $1,25-(\mathrm{OH})_{2} \mathrm{D}_{3}$. In addition, $\mathrm{SH}$ rats older than 17 wk develop hypercalciuria, which is consistent with a defect in calcium transport by the renal tubule (7). To examine possible defects in the animal model, we measured vitamin D metabolites in serum and calcium absorption by the small intestine in SH rats and normotensive WKy controls.

\section{Methods}

Animals. Weanling male rats that weighed at least $35 \mathrm{~g}$ (mean body weights at $23 \mathrm{~d}$ : WKy $=57 \mathrm{~g}$ and $\mathrm{SH}=53 \mathrm{~g}$ ) were obtained from the SH-WKy breeder colonies of The University of Iowa Cardiovascular Center (Iowa City, IA). Groups of animals from weekly litters were housed individually in metabolic cages and weighed weekly. Animals were fed Purina Chow 5012 (1.01\% calcium, 0.74\% phosphorous, $0.21 \%$ magnesium, 3.3 IU vitamin D per g; Ralston Purina Co., St. Louis, MO) ad lib and allocated randomly for calcium transport measurements or drawing of blood. Food intake of ad lib-fed, 12-wk-old SH rats was slightly greater than that of WKy rats. To evaluate the effect of this difference in food intake on $1,25-(\mathrm{OH})_{2} \mathrm{D}_{3}$ in one set of studies, $\mathrm{SH}$ rats were divided into two groups when they began to eat more. One SH group was pair-fed to the mean intake of WKy animals, and the other SH group was fed ad lib. In this experiment all animals were used for measuring vitamin D metabolites in serum. Animals were exsanguinated from the aorta to measure serum concentrations of calcium and magnesium by atomic absorption, phosphorous (13), and vitamin D metabolites by the method of Horst et al. (14). Blood pressure was measured with an electrosphygmomanometer (model AMS6; IITC, Inc., Landing, $\mathrm{NJ}$ ) and recorded (model R511 dynograph; Beckman Instruments Inc., Fullerton, CA) at weekly intervals beginning at 6 wk.

Transport studies. Calcium transport was measured in vitro at 5 and $12 \mathrm{wk}$ using everted duodenal sacs as previously described (15) and a $0.4 \mathrm{mM}$ calcium chloride solution that contained tracer ${ }^{45} \mathrm{Ca}(15 \mu \mathrm{Ci} /$ liter; $34 \mathrm{mCi} / \mathrm{mg}$, New England Nuclear, Boston, MA), $151 \mathrm{mM}$ sodium chloride, $20 \mathrm{mM}$ glucose, and $4 \mathrm{mM} \mathrm{NaHPO}_{4}$, adjusted to $\mathrm{pH}$ 7.2. The segment of small intestine $(8 \mathrm{~cm}$ in 5 -wk-old animals and $10 \mathrm{~cm}$ in 12 wk-old animals) immediately distal to the pylorus was used. The bile duct was ligated, the segment was stripped from the mesentery, everted, and tied at one end. In the 5-wk-old animals, the serosal side of the sac was filled with $0.5 \mathrm{ml}(0.75 \mathrm{ml}$ in $12 \mathrm{wk}$ animals) of the solution described above. Methods for incubation, measurement of water movement, and analysis of calcium and ${ }^{45} \mathrm{Ca}$ has been described previously (15). Calcium transport is expressed as ${ }^{45} \mathrm{Ca}$ concentration ratios of serosal-to-mucosal (S/M) media and as net calcium transport into the serosal medium.

Calcium transport was measured in vivo at $12 \mathrm{wk}$ by in situ luminal perfusion of proximal and distal segments of small intestine (16). 20$\mathrm{cm}$-long segments of the most proximal small intestine just distal to the pylorus, and of the most distal small intestine just proximal to the cecum, were cannulated. An isotonic saline solution (12 ml) that contained various concentrations of calcium, tracer ${ }^{45} \mathrm{Ca}$, and phenol red $(5 \mathrm{mg} / 100 \mathrm{ml})$ was recirculated with a peristaltic pump from a reservoir through each segment at $2 \mathrm{ml} / \mathrm{min}$ for $2 \mathrm{~h}$. After $2 \mathrm{~h}$ the luminal contents were drained into the reservoir, the perfused segments were excised, and their length and weight were measured. Calcium and ${ }^{45} \mathrm{Ca}$ were analyzed as above, and phenol red was analyzed colorimetrically (17). After correction for net water movement, net calcium absorption was calculated from initial and final calcium concentration, and flux of calcium out of the lumen into the animal (influx) was calculated from ${ }^{45} \mathrm{Ca}$ data as previously described (16). Data were analyzed statistically by the $t$ test.

\section{Results}

In preliminary studies we measured food intake of groups of 5-wk-old SH and WKy rats of the same initial weight. Food intake was slightly greater in SH rats, and they grew more rapidly than WKy rats from 5 to 12 wk. Food intake per gram body weight was the same for both groups. To assess the effect of the difference in food intake (15\% greater in $\mathrm{SH}$ ), we pair-fed half of the SH rats with the WKy group and fed the remainder ad lib for two more weeks. Serum $1,25-(\mathrm{OH})_{2} \mathrm{D}_{3}$ did not differ significantly among groups: WKy, 53 \pm 7 ; SH ad-lib fed, 44 \pm 6 ; SH pair-fed, $33 \pm 3 \mathrm{pg} / \mathrm{ml}$, mean \pm SE. We concluded that the small difference in calcium intake between $\mathrm{SH}$ and WKy rats fed ad lib had no significant effect on $1,25-(\mathrm{OH})_{2} \mathrm{D}_{3}$. In all other experiments animals were fed ad lib, conforming with most previous studies.

Body weight and the weight and length of intestinal segments of animals used in transport studies are shown in Table I. In vitro transport was examined at 5 and $12 \mathrm{wk}$ and in vivo studies were done at $12 \mathrm{wk}$. At $5 \mathrm{wk}$, body weight and segment length were the same in WKy and SH animals. Duodenal weights, however, were greater in SH rats at 5 and 12 wk. Mean values for body and segment weight for 12-wk old animals were also greater in SH animals, but the difference was not always significant. Segment lengths did not differ significantly. Segment thickness (weight/length; data not shown) was also calculated; mean thickness was greater in SH rats for both segments, but the increase was significant only for the proximal segment $(P$ $<0.025$ ). All proximal segments were thicker than distal segments $(P<0.05)$.

Table II shows systolic blood pressure of a group of 55 representative animals during these studies. After $7 \mathrm{wk}$, blood pressure became significantly greater in SH than in WKy rats.

Fig. 1 shows data from in vitro calcium transport studies of $\mathrm{S} / \mathrm{M}$ concentration ratios of ${ }^{45} \mathrm{Ca}$ developed by everted sacs of duodenum of 5- and 12-wk-old animals after $60 \mathrm{~min}$ of incubation. The younger animals developed significantly greater concentration ratios than the older animals $(P<0.05)$, and at both 5 and 12 wk the concentration ratio was lower in the $\mathrm{SH}$ group $(P<0.001)$. At 12 wk the $\mathrm{S} / \mathrm{M}$ gradient for $\mathrm{SH}$ animals was small (1.4), but greater than unity. Net calcium transport into the serosal medium per unit weight of mucosa of duodenal sacs showed the same pattern as ${ }^{45} \mathrm{Ca}$ concentration ratios of Fig. 1: decreased transport in the SH animals $(P<0.001)$ at both 5 and $12 \mathrm{wk}$ and lower values in older rats $(P<0.05)$.

Results of in vivo studies are shown in Figs. 2-5. Fig. 2 shows, for proximal small intestine of 12-wk-old SH and WKy rats, the relationship between calcium influx and luminal con- 
Table I. Body Weight and Weight and Length of Intestinal Segments of Rats Used in Transport Studies (Mean \pm SE)

\begin{tabular}{|c|c|c|c|c|c|c|}
\hline \multirow[b]{2}{*}{ Group $(n)$} & \multirow[b]{2}{*}[\mathrm{Ca}^{++}]{$^{*}$} & \multirow{2}{*}{$\begin{array}{l}\text { Body } \\
\text { weight }\end{array}$} & \multicolumn{4}{|c|}{ Segments studied } \\
\hline & & & \multicolumn{2}{|c|}{ Length† } & \multicolumn{2}{|c|}{ Wet weight } \\
\hline & $m M$ & $g$ & \multicolumn{2}{|c|}{$\mathrm{cm}$} & \multicolumn{2}{|c|}{$m g$} \\
\hline In vitro studies & & & \multicolumn{2}{|c|}{ Duodenum } & \multicolumn{2}{|c|}{ Duodenum } \\
\hline \multicolumn{7}{|c|}{ 5-wk-old animals } \\
\hline WKy (8) & 0.4 & $105 \pm 4$ & \multicolumn{2}{|c|}{8} & \multicolumn{2}{|c|}{$601 \pm 16$} \\
\hline SH (9) & 0.4 & $114 \pm 4$ & \multicolumn{2}{|c|}{8} & \multicolumn{2}{|c|}{$692 \pm 15^{\prime \prime}$} \\
\hline \multicolumn{7}{|c|}{ 12-wk-old animals } \\
\hline WKy (8) & 0.4 & $279 \pm 6$ & \multicolumn{2}{|c|}{10} & \multicolumn{2}{|c|}{$831 \pm 17$} \\
\hline SH (11) & 0.4 & $314 \pm 6^{\prime \prime}$ & \multicolumn{2}{|c|}{10} & \multicolumn{2}{|c|}{$1,008 \pm 31^{11}$} \\
\hline In vivo studies§ & & & Proximal & Distal & Proximal & Distal \\
\hline WKy (6) & 0 & $293 \pm 8$ & $\overline{21.2 \pm 1.1}$ & $\overline{20.4 \pm 1.5}$ & $\overline{1,193 \pm 73}$ & $\overline{1,218} \pm 176$ \\
\hline SH (6) & 0 & $320 \pm 3^{\prime \prime}$ & $20.5 \pm 1.0$ & $23.1 \pm 1.5$ & $1,397 \pm 56$ & $1,338 \pm 83$ \\
\hline WKy (6) & 0.6 & $284 \pm 10$ & $20.9 \pm 1.2$ & $17.4 \pm 0.6$ & $1,177 \pm 87$ & $1,070 \pm 89$ \\
\hline SH (6) & 0.6 & $322 \pm 4^{\prime \prime}$ & $23.3 \pm 1.0$ & $22.1 \pm 2.0$ & $1,592 \pm 57^{\prime \prime}$ & $1,431 \pm 128$ \\
\hline WKy (8) & 2.0 & $288 \pm 7$ & $20.0 \pm 0.9$ & $22.2 \pm 1.4$ & $1,211 \pm 64$ & $1,434 \pm 138$ \\
\hline SH (8) & 2.0 & $309 \pm 7$ & $21.1 \pm 0.9$ & $22.6 \pm 1.5$ & $1,476 \pm 51^{11}$ & $1,471 \pm 115$ \\
\hline WKy (7) & 3.4 & $293 \pm 7$ & $22.1 \pm 1.3$ & $18.9 \pm 1.7$ & $1,165 \pm 60$ & $1,010 \pm 97$ \\
\hline SH (10) & 3.4 & $324 \pm 6^{\prime \prime}$ & $21.5 \pm 0.6$ & $19.0 \pm 1.8$ & $1,290 \pm 61$ & $1,106 \pm 130$ \\
\hline WKy (7) & 6.8 & $281 \pm 10$ & $19.1 \pm 1.0$ & $18.9 \pm 1.9$ & $1,070 \pm 51$ & $950 \pm 72$ \\
\hline SH (7) & 6.8 & $299 \pm 6$ & $21.1 \pm 1.3$ & $20.9 \pm 1.8$ & $1,422 \pm 92$ & $1,375 \pm 146$ \\
\hline
\end{tabular}

* $\left[\mathrm{Ca}^{++}\right]$is initial calcium concentration of the solution used in the transport study. † Segment length measured at the time of preparation of sac. For in vivo studies, segment lengths were measured at the end of the absorption study. § All in vivo studies were performed at 12 wk. "SH $>$ WKy, $P<0.01$.

centration of calcium over the range of 0-6.8 mM. Influx rate increases steeply at low concentrations and flattens at high concentrations, approaching a limiting value. This is consistent with a saturable mediated process that follows Michaelis-Menten kinetics. Data were analyzed by the method of Lineweaver and Burk (18) and $K_{\mathrm{t}}{ }^{2}$ and maximum velocity $\left(V_{\max }\right)$ were calculated (Table III). The curves shown in Fig. 2 were calculated with these constants. The calculated curves closely fit the experimental points. Constants calculated by the Eadie-Hofstee plot (19) were

2. $K_{\mathrm{t}}$ is used for transport kinetics and is analogous to $K_{\mathrm{m}}$, used for enzyme kinetics. similar. $K_{\mathrm{t}}$ values for proximal segment calcium transport in WKy and SH rats did not differ, but $V_{\max }$ was significantly decreased in SH rats. The decrease in $V_{\max }$ is consistent with the significantly lower calcium influx in $\mathrm{SH}$ at each concentration point (Fig. 3).

Fig. 3 shows a similar plot of calcium influx for distal small intestine of SH and WKy rats. Data were analyzed as described above for the proximal segment and showed $K_{\mathrm{t}}$ to be the same in both SH and WKy rats but $V_{\max }$ to be significantly lower in SH rats (Table III). At all concentrations, mean influx was lower in SH than in WKy rats, but the differences were not significant.

Figs. 4 and 5 show the net calcium absorption data corre-

Table II. Blood Pressure

\begin{tabular}{llllllll}
\hline & \multicolumn{7}{c}{ Age (weeks) } \\
\cline { 2 - 7 } Group & 6 & 7 & 8 & 9 & 10 & 11 & 12 \\
\hline & & & & Torr, mean $\pm S E$ & & $135 \pm 0$ & $134 \pm 8$ \\
WKy & $100 \pm 10$ & $122 \pm 4$ & $124 \pm 5$ & $135 \pm 6$ & $134 \pm 8$ & $135 \pm 9$ & $188 \pm 7$ \\
SH & $127 \pm 6$ & $143 \pm 4$ & $163 \pm 2$ & $167 \pm 4$ & $176 \pm 4$ & $176 \pm 4$ & $<0.001$ \\
WKy vs. SH, $P$ value & $>0.05$ & $>0.05$ & $<0.01$ & $<0.001$ & $<0.001$ & $<0.001$ & \\
\hline
\end{tabular}




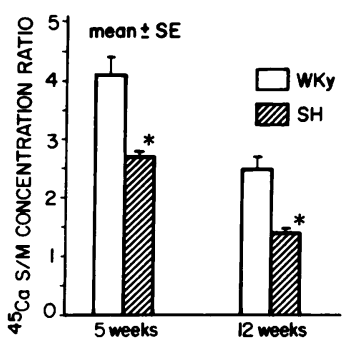

Figure 1. In vitro studies. S/M concentration ratios of ${ }^{45} \mathrm{Ca}$ developed at $1 \mathrm{~h}$ by everted duodenal sacs of WKy and $\mathrm{SH}$ rats at 5 and 12 wk of age. The younger animals developed a significantly greater concentration ratio $(P<0.05)$ than the older animals. The ratio for $\mathrm{SH}$ animals was lower than for WKy rats at corresponding time intervals $(P<0.001)$. WKy animals are normotensive. SH animals are normotensive at $5 \mathrm{wk}$ and hypertensive at 12 wk. *WKy and SH data differ significantly.

sponding to data from the influx studies plotted in Figs. 2 and 3. Over the entire concentration range, mean net absorption in the proximal segment is lower $(P<0.01)$ in SH than in WKy rats (Fig. 4). The slightly lower mean net absorption data in the distal segment of SH rats do not differ significantly from WKy data (Fig. 5). Calcium efflux, calculated as the difference between influx (Figs. 2 and 3) and net absorption (Figs. 4 and 5) data, was independent of luminal calcium concentration and did not differ in WKy and SH groups.

Net sodium and water absorption during calcium absorption studies are shown in Fig. 6. In the proximal segment, mean net sodium and water absorption were greater in SH than in WKy rats. There was no difference in the distal segment between SH and WKy groups.

Serum concentration of vitamin D metabolites, total serum calcium, magnesium, and inorganic phosphorus at $12 \mathrm{wk}$ are shown in Table IV. Data are from a separate group of ad libfed animals and show no significant difference between WKy and $\mathrm{SH}$ rats for $1,25-(\mathrm{OH})_{2} \mathrm{D}_{3}$ and 24,25-dihydroxycholecal-

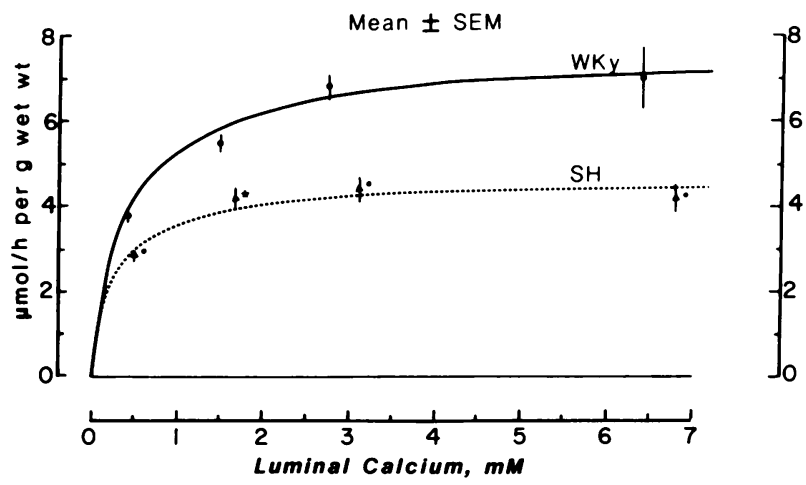

Figure 2. In vivo studies. Proximal small intestine of 12-wk-old WKy and SH rats: relationship between calcium influx and luminal calcium concentration. Data points follow Michaelis-Menten kinetics. Analysis by method of Lineweaver and Burk (18) shows $K_{\mathrm{t}}$ to be the same in WKy and SH rats, but $V_{\max }$ to be decreased in $\mathrm{SH}$ $(P<0.05)$ (Table III). Curves were calculated from $K_{\mathrm{t}}$ and $V_{\max }$ values and fit experimental data points closely. ${ }^{*} \mathrm{WKy}$ and SH data differ significantly.
Table III. Kinetic Constants (Mean士SEM)

\begin{tabular}{lccccc}
\hline & \multicolumn{2}{c}{ Proximal } & & \multicolumn{2}{c}{ Distal } \\
\cline { 2 - 3 } \cline { 5 - 6 } & WKy & $\mathrm{SH}$ & & WKy & $\mathrm{SH}$ \\
\hline Influx data & & & & \\
$K_{\mathrm{t}}(\mathrm{mM})$ & $0.47 \pm 0.10$ & $0.27 \pm 0.10$ & & $0.13 \pm 0.04$ & $0.14 \pm 0.06$ \\
$V_{\max }^{*}$ & $7.6 \pm 0.4$ & $4.6 \pm 0.3 \dagger$ & $3.0 \pm 0.1$ & $2.5 \pm 0.1 \dagger$ \\
Net absorption data & & & & \\
$K_{\mathrm{t}}(\mathrm{mM})$ & $0.78 \pm 0.56$ & $0.56 \pm 0.54$ & & $1.3 \pm 0.5$ & $1.1 \pm 1.0$ \\
$V_{\max }$ & $07.1 \pm 1.4$ & $3.8 \pm 1.0$ & & $2.8 \pm 0.6$ & $1.9 \pm 0.8$ \\
\hline
\end{tabular}

* Micromoles per hour per gram wet weight segment. † SH less than WKy, $P$ $<0.05$.

ciferol $\left[24,25-(\mathrm{OH})_{2} \mathrm{D}_{3}\right]$. Concentration of 25-hydroxycholecalciferol $\left(25-\mathrm{OH}-\mathrm{D}_{3}\right)$ is more than one and one-half times greater in SH than in WKy rats. Although mean values for serum calcium and inorganic phosphorus were slightly lower, and for magnesium slightly higher, in SH rats, differences were not significant.

\section{Discussion}

These studies demonstrate defects in intestinal calcium transport and vitamin D metabolism in SH as compared with WKy rats. The ability to develop a transmucosal calcium concentration gradient in vitro was decreased in the proximal small intestine, and $V_{\max }$ for in vivo calcium transport was decreased in both the proximal and distal small intestine of SH rats. Despite the defect in calcium transport, sodium and water transport were increased in the proximal small intestine of SH rats. Thus, there is no generalized depression of transport in SH rats. Because, based on in vitro studies, the defect in calcium transport is present before a significant difference in blood pressure, it is not secondary to the elevated blood pressure and could be a

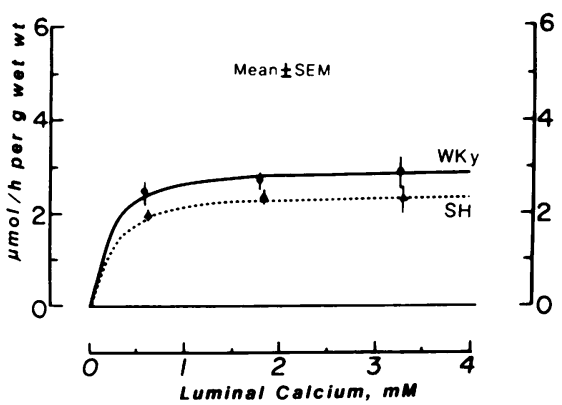

Figure 3. In vivo studies. Distal small intestine of 12-wk-old WKy and SH rats: relationship between calcium influx and luminal calcium concentration. Analysis of transport data as for the proximal segment (Fig. 2) showed $K_{\mathrm{t}}$ to be the same in SH and WKy rats, but $V_{\max }$ to be lower in SH $(P<0.05)$ (Table III). 


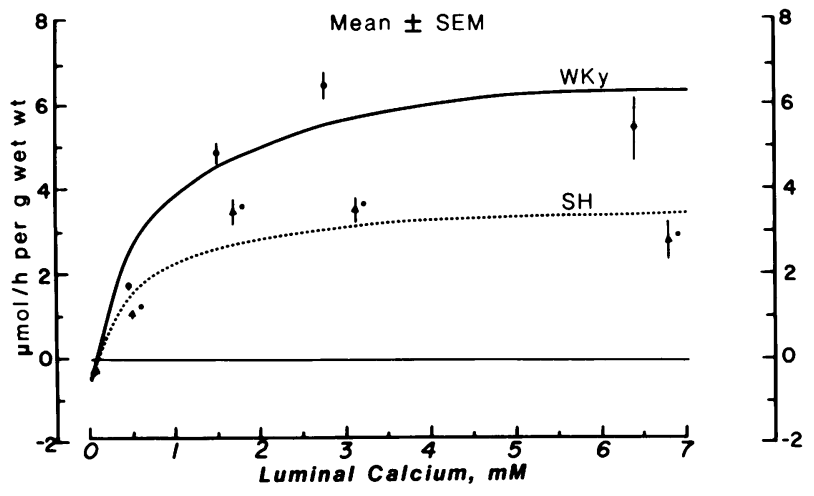

Figure 4. In vivo studies. Proximal small intestine of 12-wk-old WKy and SH rats: relationship between net calcium absorption and luminal calcium concentration. Transport data were analyzed as in Fig. 2. $K_{\mathrm{t}}$ was the same in $\mathrm{SH}$ and WKy rats, $V_{\max }$ was lower in SH rats, but not significantly (Table III). Over the entire concentration range, mean net absorption in the proximal segment is lower in SH than in WKy rats $\left({ }^{*} P<0.01\right)$.

contributing factor in the development of hypertension. The defect in calcium transport and the development of hypertension in the SH rat may also be genetically linked but causally unrelated, and the calcium transport defect may appear at an earlier age than does the elevation in blood pressure.

Vitamin D deficiency produces a defect in $\mathrm{Ca}^{2+}$ transport that has the same characteristics that appear in the SH rat. The vitamin D-depleted rat studied in vitro using everted duodenal sacs has a decreased capacity to develop an S/M concentration gradient for calcium (20-23). In vivo, vitamin $\mathrm{D}$ depletion in the rat decreases net absorption of $\mathrm{Ca}^{2+}$ by decreasing flux out of the lumen (23) but does not affect flux into the lumen, whether measured directly (24) or indirectly (23) as in the present study. However, this defect in calcium transport occurs in the setting of the same serum concentration of $1,25-(\mathrm{OH})_{2} \mathrm{D}_{3}$ in $\mathrm{SH}$ and WKy animals. Thus, the defect may be the result of resistance of the small intestine of SH rats to vitamin D action.

Evidence for vitamin D resistance in the 12-wk-old SH rat

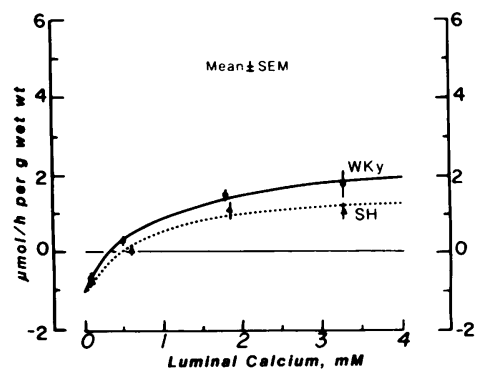

Figure 5. In vivo studies. Distal small intestine of 12wk-old WKy and SH rats: relationship between net calcium absorption and luminal calcium concentration. Transport data were analyzed as in Fig. 2, and showed no difference between WKy and SH rats. The slightly lower mean net calcium absorption in the distal segment of SH rats is not significantly different from that of WKy animals.

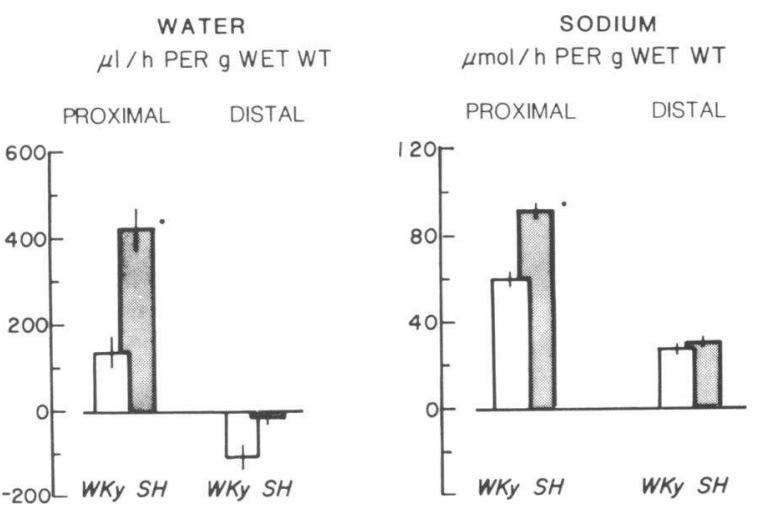

Figure 6. In vivo studies. Proximal and distal small intestine of 12 wk-old WKy and SH rats: net flux (mean \pm SEM) of water (left) and sodium (right) during net absorption of calcium (combined data from all studies: WKy, $n=34$; SH, $n=37$ ). Transport of water and sodium in the proximal segments was greater in $\mathrm{SH}$ animals $\left({ }^{*} P\right.$ $<0.05$ ), but did not differ in the distal segment.

is provided by an earlier study (25). Pharmacologic doses of $1,25-(\mathrm{OH})_{2} \mathrm{D}_{3}$ (30 $\mathrm{ng}$ for in vitro sac studies and $100 \mathrm{ng}$ for in vivo perfusion studies) failed to increase duodenal calcium transport above the basal level in the SH rat, although the WKy rat responded. This dose of $1,25-(\mathrm{OH})_{2} \mathrm{D}_{3}$ is 3 to 11 times that required to produce a maximum in vitro transport response. Further studies are required to determine if the small intestine is vitamin $D$ resistant or if there is an intrinsic defect in the transport process for calcium.

Vitamin $D$ resistance can be examined by measuring mucosal vitamin D receptors, but if these are normal, a post-receptor defect may be present. Vitamin $D$ acts at the brush border to control calcium entry as well as on the calcium extrusion process at the basolateral cell membrane, and it may be involved in the transit of intracellular calcium from the brush border to the basolateral cell membrane through vitamin D-dependent in-

Table IV. Serum Concentrations of Vitamin D Metabolites, Total Calcium, Magnesium, and Inorganic Phosphorus in Ad Lib-Fed $S H$ and WKy Rats at 12 Wk (Mean $\pm S E$ )

\begin{tabular}{lcc}
\hline Substance & WKy & SH \\
\hline Number of animals & 13 & 22 \\
$1,25-(\mathrm{OH})_{2} \mathrm{D}_{3}(\mathrm{pg} / \mathrm{ml})$ & $62 \pm 5$ & $71 \pm 5$ \\
$25-\mathrm{OH}-\mathrm{D}_{3}(\mathrm{ng} / \mathrm{ml})$ & $23.9 \pm 0.5$ & $38.5 \pm 0.6^{*}$ \\
$24,25-(\mathrm{OH})_{2} \mathrm{D}_{3}(\mathrm{ng} / \mathrm{ml})$ & $2.8 \pm 0.4$ & $2.3 \pm 0.3$ \\
Calcium $(\mu \mathrm{M})$ & $2504 \pm 31$ & $2444 \pm 18$ \\
Magnesium $(\mu \mathrm{M})$ & $897 \pm 1$ & $946 \pm 16$ \\
Inorganic phosphorus & & \\
$\quad(\mathrm{mg} / 100 \mathrm{ml})$ & $7.3 \pm 0.2$ & $6.5 \pm 0.3$ \\
& &
\end{tabular}

* WKy $>$ SH, $P<0.05$. 
testinal calcium binding protein. Because of these multiple actions of vitamin $D$, distinguishing a primary calcium transport defect from one secondary to vitamin $\mathrm{D}$ resistance will be difficult.

The kidney may also be involved in this transport defect. Although urinary calcium excretion is similar in young $\mathrm{SH}$ and WKy rats, for example, at $12 \mathrm{wk}$ of age (7) and at 11-17 wk of age (26), urinary calcium excretion is greater in $\mathrm{SH}$ than in WKy rats from week 17 onward and by 43 wks is almost four times greater in the $\mathrm{SH}$ rat (7). Elevated renal calcium excretion could contribute to the decreased serum ionized calcium in the older animals. Although not demonstrable by measurement of urine calcium in young animals, a genetic defect similar to that which we found in the enterocyte may be present in the renal tubule cell, which is also a target for $1,25-(\mathrm{OH})_{2} \mathrm{D}_{3}$.

Earlier studies have shown that concentrations of ionized calcium in serum is reduced $(7,10,11)$ and that parathyroid hormone is higher in SH than in WKy rats (7). In this context, the finding of the same concentration of $1,25-(\mathrm{OH})_{2} \mathrm{D}_{3}$ in serum of both groups is paradoxical: $\mathrm{SH}$ rats are not responding to the stimulus to increase $1,25-(\mathrm{OH})_{2} \mathrm{D}_{3}$. This is most consistent with a defect in regulation of $1,25-(\mathrm{OH})_{2} \mathrm{D}_{3}$ production, especially in the context of elevated $25-\mathrm{OH}-\mathrm{D}_{3}$ in $\mathrm{SH}$ rats. To define the nature of the abnormality in vitamin $\mathrm{D}$ metabolism, further study will be needed.

Our calcium transport studies agree with earlier data in the rat that show a higher rate of calcium absorption in proximal than in distal small intestine (27-29). A previous study examined duodenal calcium transport in SH and WKy rats at 5 and 12 wk using everted sacs and in vivo perfusion (25). SH and WKy rats developed the same $S / M$ concentration ratios at $5 \mathrm{wk}$, but at 12 wk the ratio was greater in SH than in WKy rats. The absolute values for $\mathrm{S} / \mathrm{M}$ ratios of 2.5 at 5 wk were low for both SH and WKy rats, considering that incubation was for $90 \mathrm{~min}$ (rather than $60 \mathrm{~min}$, as in this study); and that the gradient was developed using $0.25 \mathrm{mM}$ calcium, so that less calcium would have to be transferred per unit increase in gradient than for the $0.4 \mathrm{mM}$ calcium used in this study. The $\mathrm{S} / \mathrm{M}$ concentration ratio developed by 12-wk-old WKy rats was lower than that developed by 5-wk-old WKy and SH rats. SH rats did not show a decline in concentration ratio at $12 \mathrm{wk}$ as compared with 5 wk. Thus, the age-related decline in $\mathbf{S} / \mathrm{M}$ ratio was present for WKy, but not for SH, rats. In vivo duodenal calcium transport studies at 12 wk confirmed in vitro studies: transport of $1 \mathrm{mM}$ calcium measured as ${ }^{45} \mathrm{Ca}$ was greater in the $\mathrm{SH}$ than in the WKy rat. As mentioned previously, these studies also demonstrated responsiveness of WKy but not of SH rats to pharmacologic doses of $1,25-(\mathrm{OH})_{2} \mathrm{D}_{3}$.

Our findings may be important in relation to hypertension in SH rats. Calcium malabsorption by the small intestine could cause calcium depletion and may explain in part the low ionized calcium in serum of SH rats. However, the large intestine also absorbs calcium (30) and may be important in calcium homeostasis. In contrast to influx studies, calcium efflux was the same in SH and WKy rats. Since we have not examined calcium transport by the large intestine in SH and WKy rats, no conclusions can be made about calcium balance. Previous studies have shown that increased dietary calcium lowers blood pressure in SH rats $(6,7)$ and in WKy rats $(6)$, and that low dietary calcium increases blood pressure in WKy rats (5). Calcium malabsorption that causes calcium depletion could therefore contribute to the development of hypertension. Studies of humans also suggest a decreased calcium intake for patients with essential hypertension (1). Patients with essential hypertension, like the SH rat, show decreased ionized calcium (9) and elevated parathyroid hormone (12) compared with normotensive controls. Thus, our findings may be relevant to essential hypertension.

Our findings of altered membrane transport of calcium and sodium by the enterocyte of the SH rat agree with the behavior of several other types of cells. The erythrocyte of the SH rat shows increased sodium and potassium permeability (31) and decreased binding of calcium to the inner membrane surface (32). The adipocyte of the SH rat shows decreased calcium binding to the membrane (33), an increased intracellular calcium pool (34), and decreased membrane fluidity (35). Calcium binding to subcellular fractions of the aortic wall (36) and aortic smooth muscle (37) is also decreased. Increased net sodium efflux (38), sodium-potassium turnover (39), and $\mathrm{Na}^{+} \mathrm{K}^{+}$-ATPase activity (40) has been demonstrated for arterial wall and smooth muscle of the SH rat. Thus, in general, in cells from the SH rat, cell-membrane permeability to sodium is increased in association with elevated $\mathrm{Na}^{+} \mathrm{K}^{+}$-ATPase activity. Two current mechanisms for calcium regulation of smooth muscle relaxation and contraction have recently been reviewed (41). The complexity of the calcium cycle precludes defining a relationship between our findings and those reviewed above to the state of tension in arterial smooth muscle.

\section{Acknowledgments}

The authors acknowledge the valuable technical assistance of Teresa Marshall and Thomas Grawe and the word-processing skills of Ella Albright and Kathleen Funk. Drs. Michael Brody, Donald Heistad, Allyn Mark, and Phillip Schmid reviewed the manuscript and provided additional valuable suggestions. We thank the Cardiovascular Center of the University of Iowa for providing the rats we studied.

This work was supported in part by the Research Service of the Veterans Administration.

\section{References}

1. McCarron, D. A., C. D. Morris, and C. Cole. 1982. Dietary calcium in human hypertension. Science (Wash. DC). 217:267-269.

2. Morris, C., J. Stanton, and D. McCarron. 1983. Human hypertension and dietary calcium. Clin. Res. 31:65A. (Abstr.)

3. Masironi, R., S. R. Koirtyohann, J. O. Pierce, and R. G. Schamschula. 1976. Calcium content of river water, trace element concentrations in toenails, and blood pressure in village populations in New Guinea. Sci. Total Environ. 6:41-53.

4. Belizan, J. M., and J. Villar. 1980. The relationship between calcium intake and edema-, proteinuria-, and hypertension-gestosis: a hypothesis. Am. J. of Clin. Nutr. 33:2202-2210. 
5. McCarron, D. A. 1982. Blood pressure and calcium balance in the Wistar-Kyoto rat. Life Sci. 30:683-689.

6. Ayachi, S. 1979. Increased dietary calcium lowers blood pressure in the spontaneously hypertensive rat. Metab. Clin. Exp. 28:1234-1238.

7. McCarron, D. A., N. N. Yung, B. A. Ugoretz, and S. Krutzik. 1981. Disturbances of calcium metabolism in the spontaneously hypertensive rat. Hypertension (Dallas). 3(Suppl I):I162-I167.

8. Chen, S., B. Eby, and K. Lau. 1982. Mechanism for the salutary effects of high diet $\mathrm{Ca}$ on blood pressure in spontaneous hypertensive rats (SHR). Proc. Am. Soc. Nephrol., 15th, Chicago. 74A. (Abstr.)

9. McCarron, D. A. 1982. Low serum concentrations of ionized calcium in patients with hypertension. $N$. Engl. J. Med. 307:226-228.

10. Wright, G. L., M. A. Toraason, J. S. Barbe, and W. Crouse. 1980. The concentrations of ionic and total calcium in plasma of the spontaneously hypertensive rat. Can. J. Physiol. Pharmacol. 58:14941499.

11. Wright, G. L., and G. O. Rankin. 1982. Concentrations of ionic and total calcium in plasma of four models of hypertension. Am. J. Physiol. 243:H365-H370.

12. McCarron, D. A., P. A. Pingree, R. J. Rubin, S. M. Gaucher, M. Molitch, and S. Krutzik. 1980. Enhanced parathyroid function in essential hypertension: a homeostatic response to a urinary calcium leak. Hypertension (Dallas). 2:162-168.

13. Fiske, C. H., and Y. Subbarow. 1925. The colorimetric determination of phosphorus. J. Biol. Chem. 66:375-400.

14. Horst, R. L., E. T. Littledike, J. L. Riley, and J. L. Napoli. 1981. Quantitation of vitamin D and its metabolites and their plasma concentrations in five species of animals. Anal. Biochem. 116:189-203.

15. Schneider, L. E., R. H. Wasserman, and H. P. Schedl. 1975. Depressed duodenal calcium absorption in the diabetic rat: restoration by Solanum Malacoxylon. Endocrinology. 97:649-653.

16. Eastin, W. C., H. D. Wilson, and H. P. Schedl. 1980. Intestinal resection and calcium absorption in the rat. Proc. Soc. Exp. Biol. Med. 163:553-557.

17. Schedl, H. P., and J. A. Clifton. 1961. Small intestinal absorption of steroids. Gastroenterology. 41:491-499.

18. Lineweaver, H., and D. Burk. 1934. The determination of enzyme dissociation constants. J. Am. Chem. Soc. 56:658-666.

19. Hofstee, B. H. J. 1959. Non-inverted versus inverted plots in enzyme kinetics. Nature (Lond.). 184:1296-1298.

20. Schachter, D., E. B. Dowdle, and H. Schenker. 1960. Active transport of calcium by the small intestine of the rat. Am. J. Physiol. 198:263-268.

21. Schachter, D., D. V. Kimberg, and H. Schenker. 1961. Active transport of calcium by intestine: action and bioassay of vitamin D. Am. J. Physiol. 200:1263-1271.

22. Urban, E., and H. P. Schedl. 1969. Comparison of in vivo and in vitro effects of vitamin $\mathrm{D}$ on calcium transport in the rat. Am. J. Physiol. 217:126-130.

23. Urban, E., and H. P. Schedl. 1970. Vitamin D, tissue calcium and calcium transport in the in vivo rat small intestine. Am. J. Physiol. 219:944-952.

24. Younoszai, M. K., E. Urban, and H. P. Schedl. 1973. Vitamin
D and intestinal calcium fluxes in vivo in the rat. Am. J. Physiol. 225:287292.

25. Toraason, M. A., and G. L. Wright. 1981. Transport of calcium by duodenum of spontaneously hypertensive rat. Am. J. Physiol. 241:G344-G347.

26. McCarron, D. A. 1983. Impaired nephrogenous cAMP response in the spontaneously hypertensive rat. Clin. Res. 31:436A. (Abstr.)

27. Krawitt, E. L., and H. P. Schedl. 1968. In vivo calcium transport by rat small intestine. Am. J. Physiol. 214:232-236.

28. Petith, M. M., and H. P. Schedl. 1976. Duodenal and ileal adaptation to dietary calcium restriction: in vivo studies in the rat. $\mathbf{A m}$. J. Physiol. 231:865-871.

29. Petith, M. M., J. R. Wenger, and H. P. Schedl. 1978. Vitamin $D$ dependence and aboral gradient of in vivo intestinal calcium transport in the rat. Am. J. Dig. Dis. 23:943-947.

30. Petith, M. M., and H. P. Schedl. 1979. Effects of diabetes on cecal and colonic calcium transport in the rat. Am. J. Physiol. 235:E699_ E702.

31. Postnov, Yu V., S. Orlov, P. Gulak, and A. Shevchenko. 1976 Altered permeability of the erythrocyte membrane for sodium and potassium ions in spontaneously hypertensive rats. Pfluegers Arch. Eur. J. Physiol. 365:257-263.

32. Postnov, Yu V., S. N. Orlov, and N. I. Pokudin. 1979. Decrease of calcium binding by the red blood cell membrane in spontaneously hypertensive rats and in essential hypertension. Pfluegers Arch. Eur. J. Physiol. 379:191-195.

33. Postnov, Yu V., and S. N. Orlov. 1980. Evidence of altered calcium accumulation and calcium binding by the membranes of adipocytes in spontaneously hypertensive rats. Pfluegers Arch. Eur. J. Physiol. 385:85-89.

34. Postnov, Yu V., S. N. Orlov, and N. I. Pokudin. 1981. Alteration of the intracellular calcium pool of adipose tissue in spontaneously hypertensive rats. Pfluegers Arch. Eur. J. Physiol. 390:256-259.

35. Orlov, S. N., and Yu V. Postnov. 1982. $\mathrm{Ca}^{++}$binding and membrane fluidity in essential and renal hypertension. Clin. Sci. (Lond.). 63:281-284.

36. Wei, J. W., R. A. Janis, and E. E. Daniel. 1976. Calcium accumulation and enzymatic activities of subcellular fractions from aortas and ventricles of genetically hypertensive rats. Circ. Res. 39:133-140.

37. Zsoter, T. T., C. Wolchinsky, N. F. Henein, and L. C. Ho. 1977. Calcium kinetics in the aorta of spontaneously hypertensive rats. Cardiovasc. Res. 11:353-357.

38. Friedman, S. M. 1979. Evidence for enhanced sodium transport in the tail artery of the spontaneously hypertensive rat. Hypertension (Dallas). 1:572-582.

39. Jones, A. W. 1974. Altered ion transport in large and small arteries from spontaneously hypertensive rats and the influence of calcium. Circ. Res. 34(Suppl. 1):117-122.

40. Webb, R. C., and D. F. Bohr. 1979. Potassium relaxation of vascular smooth muscle from spontaneously hypertensive rats. Blood Vessels. 16:71-79.

41. Kuriyama, H., Y. Ito, H. Suzuki, K. Kitamura, and T. Itoh. 1982. Factors modifying contraction relaxation cycle in smooth muscle. Am. J. Physiol. 243:H641-H662. 